\title{
DESIGN OF CONCRETE CHIMNEYS VIA BEAM THEORY AND NONLINEAR SHELL ANALYSIS
}

\author{
Franziska WeHR*, ReINHARD HARTE
}

\author{
University of Wuppertal, Pauluskirchstr. 7, 42285 Wuppertal, Germany \\ * corresponding author: fwehr@uni-wuppertal.de
}

\begin{abstract}
This paper compares the load-bearing capacity of chimneys calculated via beam and shell theory. It becomes apparent that the design via beam theory is on the safe side for the vertical reinforcement of the chosen examples for $h / d$ ratios larger than 30. For non-slender chimneys the design via beam theory overestimates the load distribution around the circumference and yields to wrong results. On the other hand a linear elastic shell calculation underestimates the load-bearing capacity of the chimney. However a realistic distribution of stresses in the cross section of a chimney can still be calculated using shell theory with nonlinear material properties.
\end{abstract}

KEYWORDS: nonlinear, shell, reinforced concrete, chimney, material nonlinear.

\section{INTRODUCTION}

Chimneys are one of the main components of thermal power plants. In design of industrial concrete chimneys the structural integrity is characterized by the ultimate limit resistance against wind action and the serviceability limit resistance against constraints caused by thermal effects. Detailed investigations on damaged chimneys [1] have shown that mechanical actions like wind load are not the only reason for the observed crack patterns. These actions have to be accompanied by constraints due to thermal effects.

\section{Design of CONCREte Chimneys VIA BEAM THEORY}

Currently the design of concrete chimneys is regulated in codes such as the international CICIND Model code for concrete chimneys [2], the EN 13084 - freestanding chimneys [3, 4] for Europe and the ACI 307-08 - code requirements for reinforced concrete chimneys [5] for the USA. A comprehensive comparison of the three codes can be found in [6]. All codes have in common that the design is performed via beam theory. A model of the whole chimney with a vertical beam and a circular cross section is used for the design of the vertical reinforcement and another model with a circular beam and a rectangular cross section for the design of the hoop reinforcement (Fig. 1). This paper focuses on the ultimate limit state (ULS) design according to CICIND model code and the European standard EN 13084 for the vertical reinforcement.

For the vertical reinforcement only mechanical impacts have to be considered. This means that usually only dead loads $G$, wind $W$, seismic actions $E$, rotations of the foundation and second order effects need to be applied. According to [2] a temperature drop in the wall may be neglected if it is less than $60 \mathrm{~K}$. Table 1 shows the load combinations for ULS design according to [2] and [4].
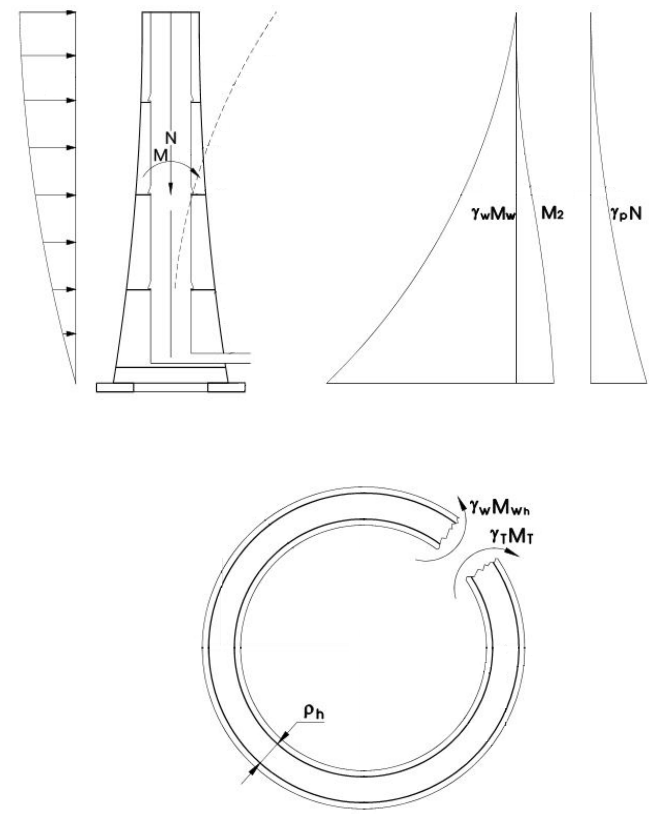

FIgURE 1. Design of concrete chimneys via two beam models (source: [2], modified)

Typical material properties for concrete (for example C30/37) and reinforcement (for example B500B) for the ULS design are shown in Fig. 2 The material properties listed in EN 13084 [4] are referring to the Eurocode [7, 8]. The diagrammed stresses in Fig. 2 are already reduced by a safety factor $\gamma$ and have to be looked upon as design values. The stress-strain-curve for concrete is identical for both considered standards, but the strain limit according to [2] is reduced to $3 \%$ instead of $3.5 \%$ according to [4]. Both standards allow only compressive stresses for concrete in ULS design. The stress-strain-curve for steel is defined to be symmetric for the compressive and tensile stresses in both codes. The steel-curves are identical up to a strain of $10 \%$. 


\begin{tabular}{llll}
\hline Verification & $\begin{array}{l}\text { Leading } \\
\text { action }\end{array}$ & $\begin{array}{l}\text { Combination of actions } \\
\text { acc. to CICIND [2] }\end{array}$ & $\begin{array}{l}\text { Combination of actions } \\
\text { acc. to EN 13084 [4] }\end{array}$ \\
\hline Vertical strength & $\begin{array}{l}\text { Inline } \\
\text { wind }\end{array}$ & $1.0 G+1.6 W+1.0 T$ & $1.0 G+1.5 W+1.0 T$ \\
\hline $\begin{array}{l}\text { Combined vertical } \\
\text { strength }\end{array}$ & $\begin{array}{l}\text { Cross } \\
\text { wind }\end{array}$ & $1.0 G+1.5 W_{\text {cross }}+1.2 W+1.0 T$ & $1.0 G+1.5 W_{\text {cross }}+1.5 W+1.0 T$ \\
\hline $\begin{array}{l}\text { Shear and flexural } \\
\text { strength }\end{array}$ & $\begin{array}{l}\text { Earth- } \\
\text { quake }\end{array}$ & $1.0 G+1.4 E+1.0 T$ & $1.0 G+1.0 E+1.0 T$ \\
\hline
\end{tabular}

TABLE 1. Combination of actions at ULS for chimneys acc. to [6].

a)
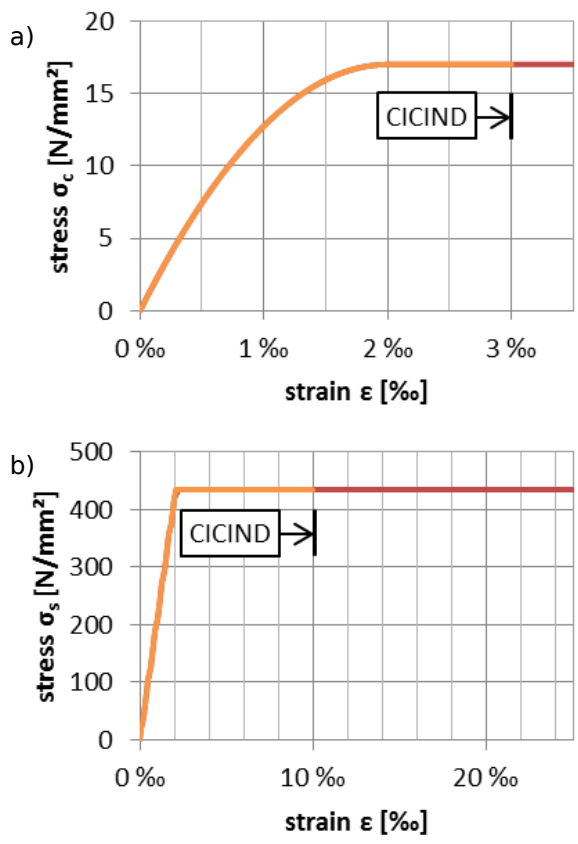

FIGURE 2. Stress-strain-curves of concrete (a) and reinforcement (b) acc. to 4, with reduced strain limits acc. to 2 .

The internal forces of the chimney are calculated using a beam model with linear-elastic material properties according to both codes. The stress resultants are combined as shown in Tab. 1. The design for the meridional reinforcement is performed by using the stress-strain-curves from Fig. 2. But it is not only a matter how the meridional stress resultants are calculated, different approaches for the design of the cross section and reinforcement need to be considered as well.

\section{COMPARISON OF BEAM THEORY AND LINEAR ELASTIC SHELL THEORY}

Further studies by 6 and 9 have revealed that for chimneys with large diameters the shell-like behavior becomes more important. It is apparent that the linear elastically calculated meridional forces of a chimney vary from a linear distribution for small diameters (Fig. 3 a) to a nonlinear distribution for larger diameters (Fig. 3 b). Fig. 3 shows the load-bearing behavior

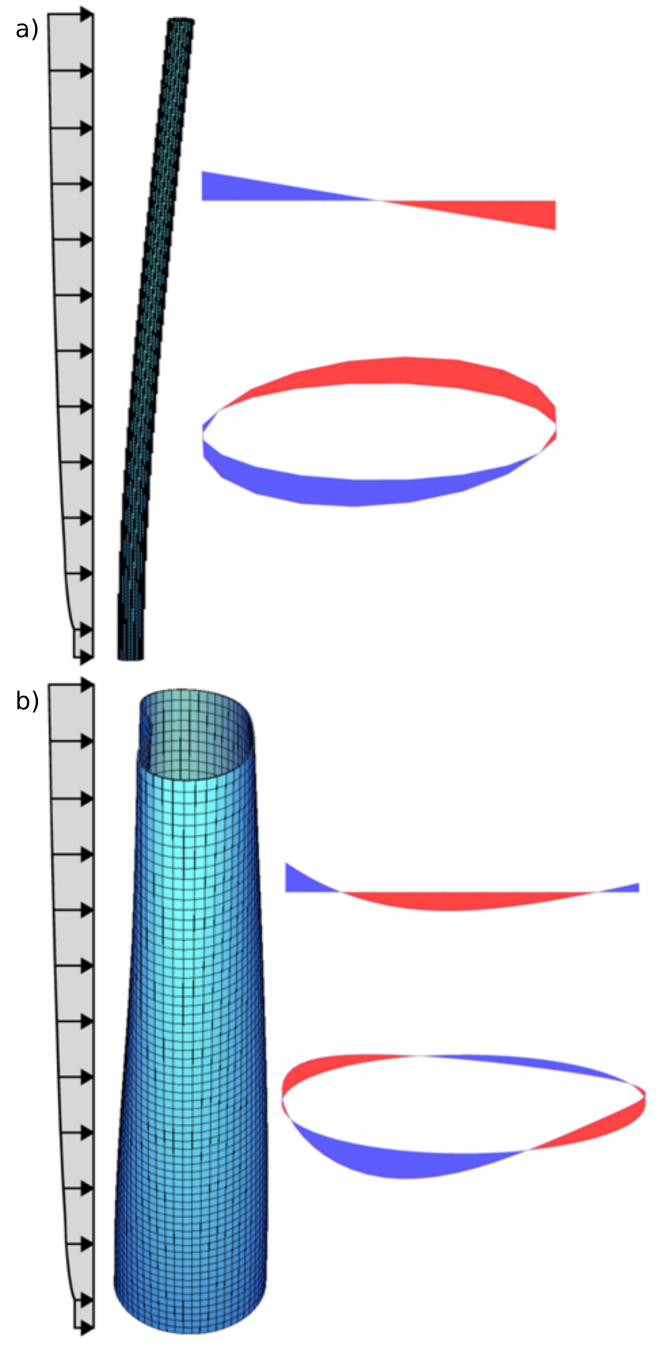

Figure 3. Meridional internal forces at the bottom for slim (a) and wide (b) cylindrical shells exposed to wind load.

of a slim and a wide cylindrical shell exposed to wind load, both calculated by shell theory. The side view of the meridional internal forces at the bottom of the slim cylinder (Fig. 3 a) shows the linear behavior of the stress resultants, as we expect it from linear elastic stress resultant calculation via beam theory, whereas for the wide cylinder (Fig. 3 b) the distribution of the meridional forces around the circumference differs significantly. It corresponds to the ovalization of 


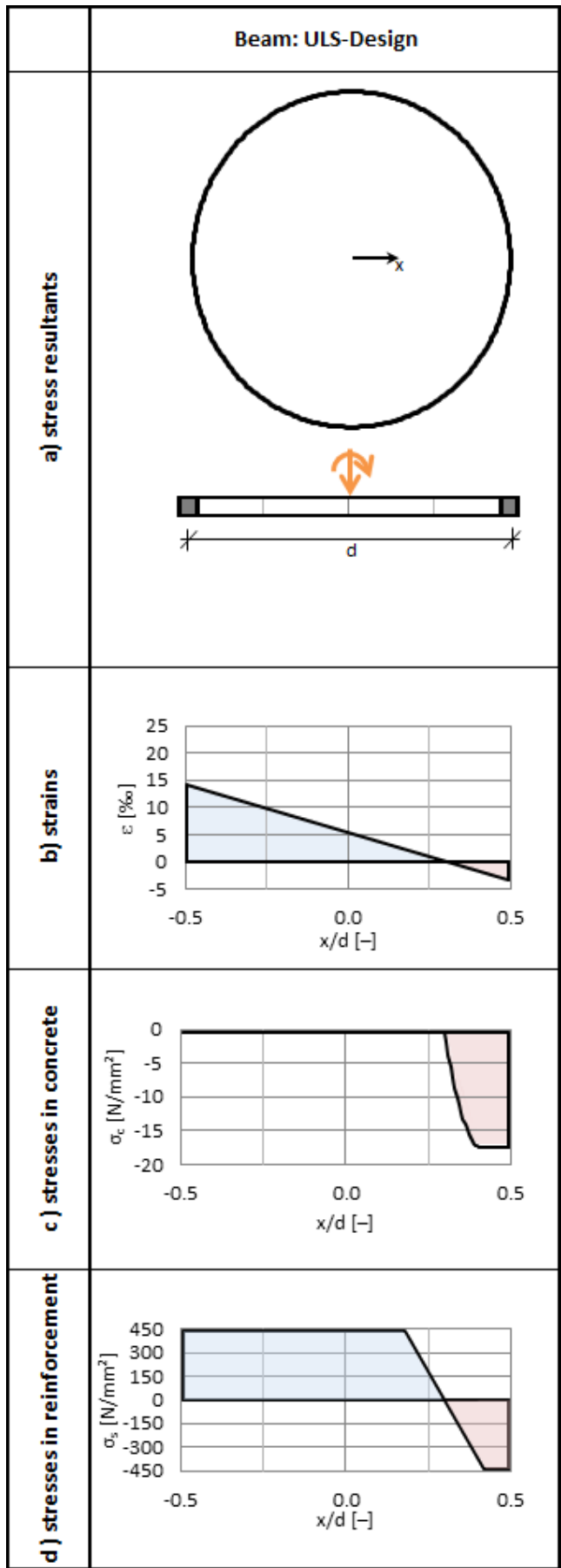

Figure 4. Design via beam theory for a specific wind load.

the circular cross section due to the reduced bending stiffness, resulting in tensile stress resultants (uplift) in both the windward and leeward side of the shell, whereas its side flanks are subjected to compressive stress resultants.

The procedure of the design according to beam theory [10] is shown in Fig. 4. A linear strain distribution is estimated for the calculated outer stress resultants according to the BERNOULLI hypothesis over the full diameter $d$ of the chimney (Fig. 4 a). This strain gradient (Fig. $4 \mathrm{~b}$ ) is varied until the respective sum of stresses in the concrete (Fig. 4 c)

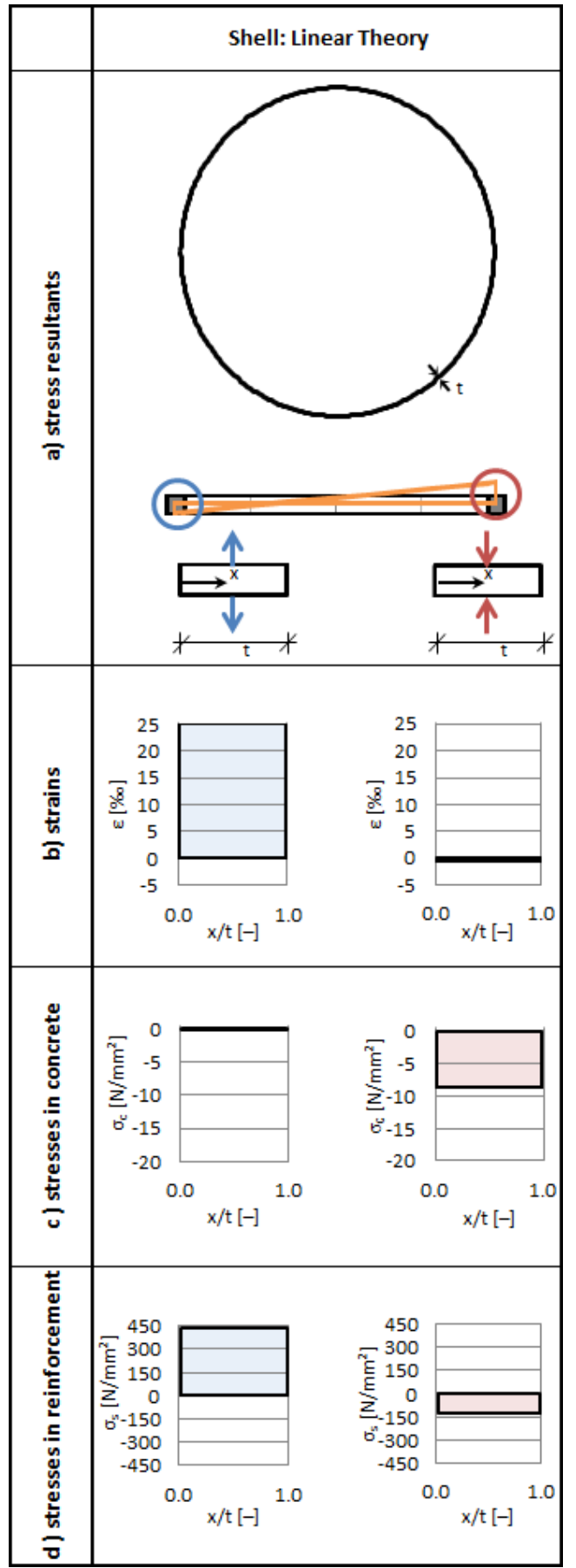

Figure 5. Design via linear elastic shell theory for a specific wind load.

and the chosen reinforcement (Fig. 4 d) result in the same stress resultants as calculated with the beam model for the considered section. So the design according to beam theory includes an implicit nonlinearity when the stress-strain-curves for concrete and steel are applied. Therefore the stress distribution for a cross section is nonlinear for outer stress resultants calculated by linear elastic beam theory (Fig. 4).

The design according to shell theory can be conducted with a linear internal stress resultant distribution over the cross section for chimneys with small diameters $d$ (Fig. 5 a). Here $t$ defines the wall thick- 
ness. The defining points for the design of the reinforcement lie in the area with maximum normal forces (Fig. 5]a) as well as in the area with minimal normal forces for the compressive strength of concrete. The decisive tensile force causes a constant strain over the wall thickness $t$ (Fig. $5 \mathrm{~b}$ ). Therefore the concrete is cracked over the entire thickness (Fig. 5 c) and the load can only be taken by the reinforcement (Fig. 5 d). Whereas the decisive compressive force can be taken up by concrete and reinforcement (Fig. $5 \mathrm{c}+\mathrm{d}$ ).

The differences in the design between beam and shell theory are now demonstrated on the basis of an example chimney. The diameter $d$ is varied while height $h$, wall thickness $t$ and reinforcement ratio $\rho$ remain constant. Three different reinforcement ratios for the vertical reinforcement are considered. The chimney is stressed by dead load $G$ and the wind load $W$ is increased gradually until either the existing reinforcement is not able to carry the load anymore or the compressive strength of the concrete is exceeded. The maximum load factor $\lambda_{\max }$ on wind load for the case of failure is plotted for each reviewed chimney with

$$
F_{E d}=1.0 \cdot G+\lambda_{\max } \cdot W=R_{E d} .
$$

The results are presented in Fig. 7) (dotted and dashed lines). For both theories in case of a slender chimney the maximal load factor is bigger for smaller $h / d$ ratios. But according to linear elastic shell theory for $h / d$-ratios smaller than about 15 the behavior changes. The reason for the smaller load bearing capacity of those chimneys is on the one hand the small reinforcement ratio for the hoop direction and on the other hand the shell-like behavior as mentioned before. According to beam theory the maximal wind load increases also for smaller $h / d$ ratios, as well for the small $h / d$ ratios not shown in Fig. 7 .

The great dissimilarities can be explained by the different design concepts for beam and shell theory which are described in Fig. 4 and 5 According to beam theory, the load is considered to act globally on the entire circular cross section whereas in shell theory the load is distributed around the circumference before performing the design for each point of the circular cross section separately. This results in a nonlinear stress distribution over the cross section according to beam theory and a linear stress distribution according to shell theory (Fig. 8, black and yellow lines). For small $h / d$ ratios the beam theory leads to wrong results, because of the consideration of a linear strain distribution. This causes a to stiff behavior of the cross section.

Since in reality stresses relocate from high stressed areas to parts with higher load-bearing capacities the solution of the beam theory seems to be more appropriate for small diameters. Nevertheless it should be verified by nonlinear shell calculations whether the load distribution really occurs the way it is assumed by beam theory.
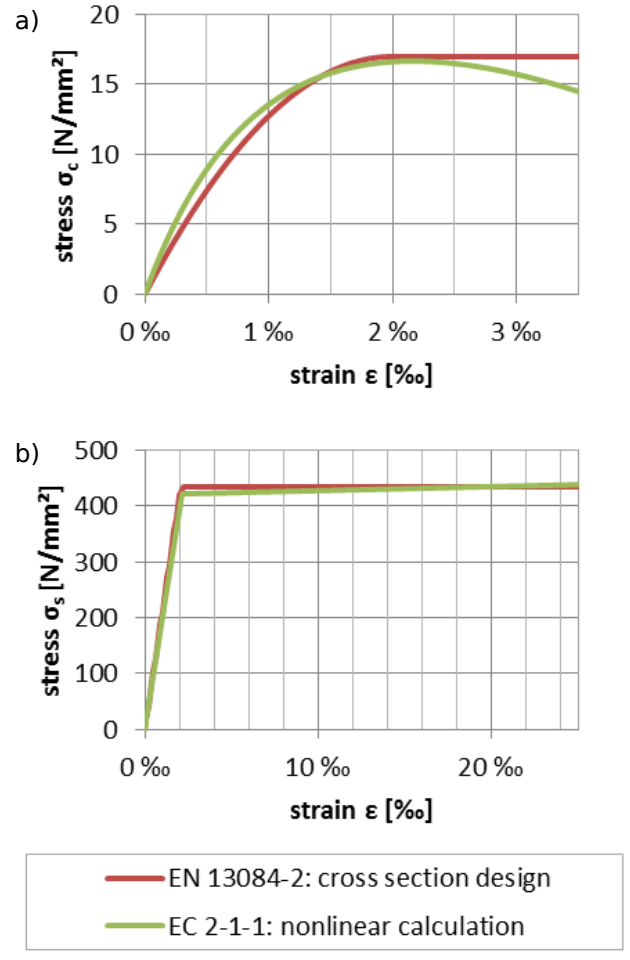

FiguRE 6. Stress-strain-curves for concrete (a) and reinforcement (b) according to [8].

\section{DESIGN CONCEPT FOR CONCRETE STRUCTURES WITH NONLINEAR MATERIAL BEHAVIOR}

It is also possible to perform a cross section design using nonlinearly calculated stresses, or by performing a nonlinear ultimate load analysis [11]. By calculating the stress resultants with nonlinear material behavior internal forces that exceed the limit strength of concrete or reinforcement are eliminated and instead relocated to less stressed areas of the cross section. This can increase the calculated load-bearing capacity of a structure compared to linear elastic shell theory.

The Eurocode [8] gives some rules for a nonlinear calculation. The material properties shown in Fig. 6 have to be used. They differ, especially for concrete, from the material properties for the design of a cross section. The displayed stress-strain-curves are already reduced by the global security factor for a nonlinear analysis in ULS.

For the nonlinear calculation according to 8 , the same load combinations as listed in Tab. 1 can be used. As it is not possible to do a superposition of the stress resultants calculated for the separate load cases, the internal forces have to be calculated for the decisive load combinations to include the nonlinear material properties. 

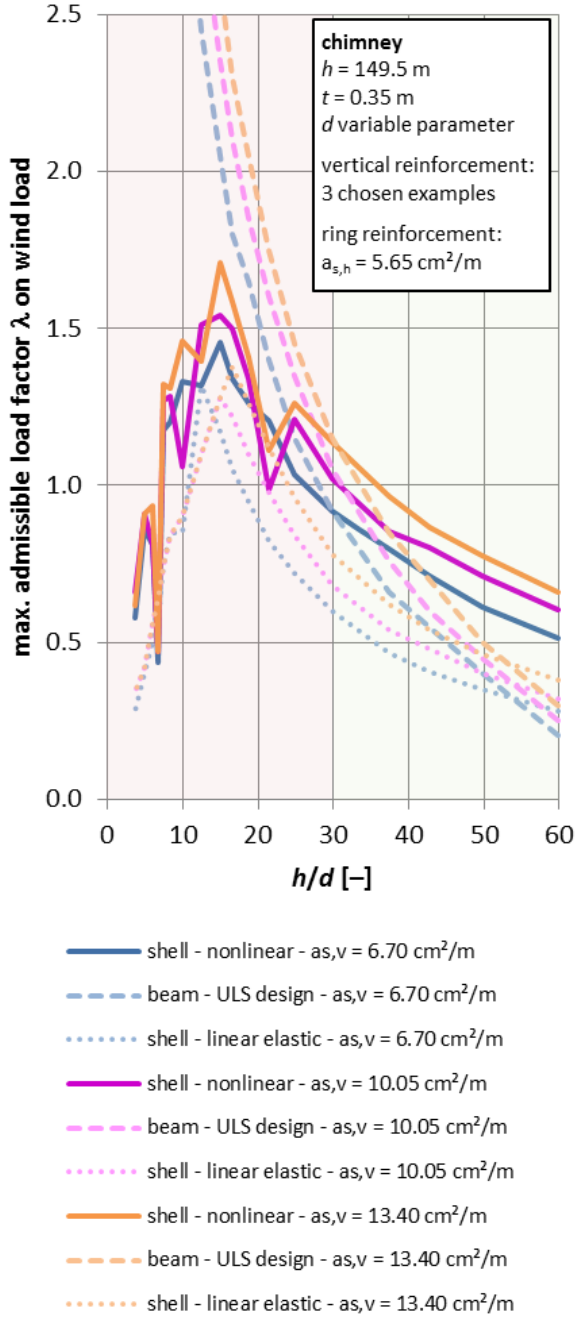

FIGURE 7. Load bearing capacity for predefined reinforcement acc. to beam theory, linear and nonlinear shell theory.

\section{COMPARISON OF DESIGN VIA BEAM THEORY AND NONLINEAR SHELL THEORY}

To compare the design results for a chimney obtained from beam theory with a nonlinear shell model the same procedure as described in chapter 3 is applied. The calculation is executed for different diameters while height and thickness remain constant. Three different reinforcement ratios are considered. The chimney is at first loaded by dead load. In the next step the wind load is added incrementally until the failure of the chimney occurs at one or several points of the shell. The maximal load factor on wind load $\lambda_{\max }$ is plotted for the failure case for each $h / d$ ratio and results in the continuous lines shown in Fig. 7 The figure clearly demonstrates that the calculated load-bearing behavior according to nonlinear shell theory is higher than according to beam theory for $h / d$ ratios larger than 30 . For smaller $h / d$ ratios the beam theory allows higher load factors $\lambda_{\max }$ than the nonlinear shell theory and thus will not be on the safe

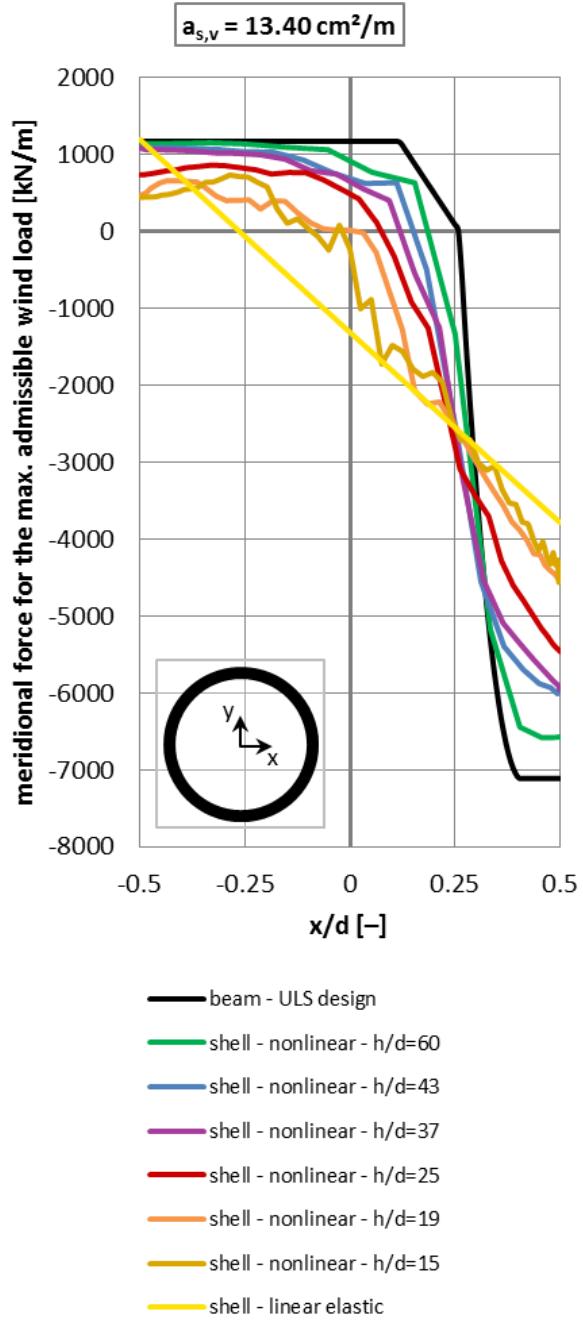

Figure 8. Comparison of meridional forces acc. to beam and shell design with respect to different ratios $h / d$.

side.

To compare the load-bearing behavior of beam and shell theory, Fig. 8 shows the vertical stress resultants over the standardized cross section in case of maximum utilization for a vertical reinforcement ratio of $13.40 \mathrm{~cm}^{2} / \mathrm{m}$. According to beam theory and linear shell theory the distribution of the normal forces is the same for all $h / d$ ratios for the given geometry, whereas according to nonlinear shell theory the distribution of the internal forces differs subjected to the $h / d$ ratios. The progression of the internal forces lies between the ones calculated by beam theory and linear elastic shell theory. For larger $h / d$ ratios the nonlinear shell curves are similar to the beam solution. The beam theory distributes the stresses in the way that the maximum tensile strength of steel and the maximum compressive strength of concrete are utilized. It can be seen that for smaller $h / d$ ratios the redistribution of the stresses around the circumference is overestimated in beam theory. Then the nonlinear shell theory is more appropriate to describe the distribution of the 
stresses. Thus for chimneys with $h / d$ ratios smaller than 30 , the calculated load-bearing capacity of the beam theory is not correct and on the unsafe side.

\section{OutLooK}

The next step will be to find out whether the results for other geometries are comparable to the presented ones. The correctness of the results according to beam theory for the ring reinforcement also needs to be checked.

If the results of further studies lead to similar results, the aim is to define a correction factor $\gamma_{c o r r}$ on wind loading as a function of slenderness ratio $h / d$ and reinforcement ratio $\rho$. The factor shall then be applied to produce correct results for concrete chimneys by using beam theory even for non-slender geometries.

\section{ACKNOWLEDGEMEnTS}

The paper has presented intermediate results from the research project "Validation of Design Procedure and Safety Concept of Concrete Chimneys via Non-linear Shell Analysis", financed by CICIND. The support by CICIND is gratefully acknowledged.

\section{REFERENCES}

[1] P. Noakowski, A. Harling, M. Breddermann, M. Rost. Rehabilitation of chimneys. CICIND Chimney Book pp. 323-344, 2005.
[2] CICIND 2001. Model code for concrete chimneys Part A: The Shell, 2011.

[3] EN 13084-1:2007. Free-standing chimneys - Part 1: General requirements, 2007.

[4] EN 13084-2:2007. Free-standing chimneys - Part 2: Concrete chimneys, 2007.

[5] ACI 307 2008. Code Requirements for Reinforced concrete Chimneys (ACI 307-08) and Commentary, 2008.

[6] R. Harte, O. Pouran. Interaction and intersection in research and development of cooling towers and concrete chimneys. CICIND Research Project RP-2013-4c. Bergische Universität Wuppertal, 2014.

[7] EN 1990:2002. Eurocode - Basis of structural design, 2002 .

[8] EN 1992-1-1:2004. Eurocode 2: Design of concrete structures - Part 1-1: General rules and rules for buildings, 2004.

[9] F. Lupi, H.-J. Niemann. International standardization of wind actions on chimneys. CICIND Research Project RP-2011-4. Ruhr-Universität Bochum and Niemann + Partner Bochum, 2013.

[10] P. Noakowski, M. Breddermann, A. Harling, M. Rost. Turmartige Industriebauwerke - Bemessungsgrundlagen der CICIND, DIN EN 13084 und DIN V 1056 mit Beispielen und Anwendungen. Beton-Kalender 2006 Turmbauwerke, Industriebauten pp. 225-318, 2006.

[11] R. Harte, W. Krätzig, S.-Y. Noh, Y. Petryna. On progressive damage phenomena of structures. Computational Mechanics 25:404-412, 2000. 